\title{
Reaction of monoclonal antibodies with species specific determinants in Leptospira interrogans outer envelope
}

\author{
B. H. JOST, B. ADLER and S. FAINE
}

Department of Microbiology, Monash University, Clayton, 3168, Victoria, Australia

\begin{abstract}
Summary. A set of 24 monoclonal antibodies (MABs) was produced against an outer envelope preparation from Leptospira interrogans serovar copenhageni. The MABs reacted in enzyme immunoassay with species-specific determinants of an antigen in the leptospiral outer envelope (OE) of pathogenic but not of saprophytic species of Leptospira. The MABs did not agglutinate whole leptospires, nor could they opsonise homologous leptospires for phagocytosis by mouse macrophages or protect new-born guinea-pigs against lethal infection. The MABs reacted by Western blotting with a $35 \times 10^{3}$-mol-wt band in OE separated on SDS-polyacrylamide gels, and also reacted with other bands to a lesser extent. The determinants to which the MABs were directed were localised in the leptospiral OE by immunogold labelling techniques.
\end{abstract}

\section{Introduction}

Leptospires are slender, helically coiled organisms surrounded by an outer envelope (OE) or sheath that encloses the protoplasmic cylinder. The protoplasmic cylinder contains the nuclear and cytoplasmic contents of the leptospire (Johnson and Faine, 1984). Thus an intact OE is essential for survival of the organism. The $\mathrm{OE}$ is approximately $11 \mathrm{~nm}$ in width and is composed of three to five electron-dense layers (Johnson, 1977). Although it is a structurally important component of the leptospire, a definite role for the $\mathrm{OE}$ in immunity to leptospirosis has not been established. OE contains lipid $35.7 \%$, protein $45.8 \%$ and carbohydrate $6.0 \%$ (Auran et al., 1975).

As agglutinating antibodies are important in immunity to leptospirosis (Adler and Faine, 1978a, $b$; Jost et al., 1986; Farrelly et al., 1987), it is probable that surface components of the leptospiral cells elicit the production of a protective humoral immune response. Auran et al. (1972) and Bey et al. (1974) described the isolation of leptospiral OE and demonstrated that this preparation was both immunogenic and able to confer protection against experimental infection. The OE preparation is very heterogeneous (Auran et al., 1975) and nothing is known about the nature, specificity or contribution of individual antigens to its protective capacity.

Received 16 Nov. 1987; accepted 11 Feb. 1988.
Anti-OE antibodies may be protective because the antibody-complement reaction has been shown to cause damage to the $\mathrm{OE}$ that leads to death of the organism (Anderson and Johnson, 1968), but the identity of these target antigens has not been elucidated.

Leptospires are classified into serovars on the basis of cross-absorption agglutination reactions with rabbit antisera. Two serovars are considered antigenically different if $10 \%$ or more of antibody titre remains after absorption with homologous serum. Clearly, agglutinating antigens are involved in these reactions, but nothing is known about the nature of the antigens.

This paper reports the production and characterisation of monoclonal antibodies (MABs) directed against components in the leptospiral OE.

\section{Materials and methods}

\section{Leptospires}

Leptospira interrogans serovar copenhageni strain $\mathrm{H} 45$ was isolated from a rat (Faine and van der Hoeden, 1964). Leptonema illini strain 3055 was obtained from A. D. Alexander, Walter Reed Army Medical Center, Washington DC, USA. The other leptospiral serovars used in this study were provided by N. Stallman, WHO Leptospira Reference Laboratory, Brisbane, Australia. Cultivation and enumeration of leptospires were as described by Adler and Faine (1976). 


\section{Antigens, antisera and serological methods}

Leptospiral OE was prepared by the method of Auran et al. (1972) and sonicated leptospires were prepared as described by Adler et al. (1980). The preparation of mouse antisera was as previously described (Tu et al., 1982), as were the methods for performing the microscopic agglutination test (MAT), gel immunodiffusion and enzyme immunoassay (EIA) (Adler and Faine, 1983a). EIA with serovar copenhageni $\mathrm{OE}$ as the antigen was performed by coating the wells of the plates with $\mathrm{OE}$ $10 \mu \mathrm{g} / \mathrm{ml}$ in phosphate-buffered saline, $\mathrm{pH} 7.2$ (PBS), instead of sonicated leptospires. Subclasses of mouse immunoglobulin were determined by reaction in gel immunodiffusion with specific anti-mouse immunoglobulins (Nordic Immunologicals, Tilburg, The Netherlands).

\section{Production of monoclonal antibodies}

Adult female BALB/c mice were immunised intraperitoneally (i.p.) with $200 \mu \mathrm{g}(0.25 \mathrm{ml})$ of serovar copenhageni $\mathrm{OE}$ emulsified with an equal volume of Freund's incomplete adjuvant. After 28 days, the mice received an i.p. booster injection of $50 \mu \mathrm{g}$ of serovar copenhageni $\mathrm{OE}$ in $0.5 \mathrm{ml}$ of water. Spleen cells were harvested 4 days later and fusion and subsequent culture and cloning of the hybrid cells were performed as described by Jost $e t$ al. (1986). After large-scale culture, cells were removed by centrifugation and culture supernate was concentrated in an Amicon $\mathrm{CH} 2$ concentrator fitted with a H1P30-43 cartridge. IgG immunoglobulins were purified by affinity chromatography with Protein A-Sepharose CL-4B (Pharmacia Fine Chemicals, Uppsala, Sweden). Protein concentration was determined by absorption at $280 \mathrm{~nm}$.

\section{Opsonisation assays and passive protection experiments}

Opsonisation and passive protection experiments were performed as previously described (Jost et al., 1986).

\section{Polyacrylamide gel electrophoresis and Western blotting}

Leptospiral antigens were electrophoresed on discontinuous sodium dodecyl sulphate (SDS)-polyacrylamide $15 \% \mathrm{w} / \mathrm{v}$ gels for $4 \mathrm{~h}$ in a Protean II gel box (Bio-Rad, USA). Electrophoresed gels were stained for protein by the silver staining method of Morrissey (1981) and for carbohydrate by the method of Hitchcock and Brown (1983). Resolved antigens were electrophoretically transferred on to nitrocellulose membranes (Bio-Rad, USA) by the method of Towbin et al. (1979) in a Bio-Rad Transblot Cell for $3 \mathrm{~h}$ at $60 \mathrm{~V}$, a 1 in 2 dilution of their described transfer buffer being used. Reactions of MABs with blotted antigens were detected by means of a peroxidaseconjugated second antibody with chloro-1-naphthol (Merck, West Germany) as the chromogen (Hawkes et al., 1982). Blotted antigens were digested with proteinase $\mathrm{K} 100 \mu \mathrm{g} / \mathrm{ml}$ (Sigma) in PBS at $37^{\circ} \mathrm{C}$ for $24 \mathrm{~h}$. Control blots were incubated in PBS. Periodate oxidation of blotted antigens was as described by Woodward et al. (1985). The production of an anti-LPS MAB designated F1-1 was reported previously (Jost et al., 1986).

\section{Affinity purification of outer envelope protein}

Twenty mg of purified (F9-10) $\mathrm{IgG}_{2 \mathrm{a}}$ was coupled to $1.0 \mathrm{~g}$ of Tresyl-activated Sepharose CL-4B (Pharmacia) according to the supplied directions. The coupled gel matrix was packed into a Pharmacia PD-10 column with PBS ; $25 \mathrm{mg}$ of serovar copenhageni OE in PBS was loaded on to the column and the unbound antigen washed through with PBS. Elution of bound OE protein was achieved with $0 \cdot 1 \mathrm{M}$ glycine- $\mathrm{HCl}$ buffer, $\mathrm{pH} 2 \cdot 7$, and the eluted fraction was measured by absorption at $280 \mathrm{~nm}$. The fraction containing purified OE protein was concentrated with an Amicon Ultrafiltration Stirred Cell fitted with a PM-10 membrane.

\section{Immune electronmicroscopy}

Leptospires were centrifuged at $3000 \mathrm{~g}$ for $30 \mathrm{~min}$ and resuspended in PBS. Immunogold labelling was performed as described by Barbour et al. (1984), with the modifications that grids were incubated for $20 \mathrm{~min}$ at room temperature in bovine serum albumin (Sigma) $1 \%$ $\mathrm{w} / \mathrm{v}$ in PBS before incubation with antibody at $37^{\circ} \mathrm{C}$ for $1 \mathrm{~h}$. PBS containing Tween 20 (Sigma) $0 \cdot 1 \% \mathrm{v} / \mathrm{v}$ was used for all washes. A 1 in 10 dilution of gold-labelled goat anti-mouse immunoglobulins (Auroprobe EM GAM G5, Jannsen Pharmaceutica, Beerse, Belgium) was used for the labelling.

\section{Results}

\section{Characterisation of $O E$ reactive $M A B S$}

MABs were of the $\operatorname{IgG}_{1}$ or $\operatorname{IgG}_{2 \mathrm{a}}$ subclass and reacted in EIA with sonicated leptospires or OE preparation, but did not agglutinate live leptospires. As the serological reactions were identical for all 24 MABs produced, the results presented will be those derived from the use of one MAB, designated F910. The MABs reacted with all serovars of the Icterohaemorrhagiae serogroup and with representative serovars of all other $L$. interrogans serogroups, but did not react with several serovars of $L$. biflexa tested, nor with Leptonema illini (table).

The MABs did not precipitate sonicated leptospiral antigen or OE preparation in gel immunodiffusion experiments, nor did they opsonise homologous leptospires for phagocytosis by murine macrophages, as determined by chemiluminescence and indirect immunofluorescence assays (re- 
Table. Reaction of MAB F9-10 with leptospiral antigens of different serovars as measured by enzyme immunoassay (EIA)

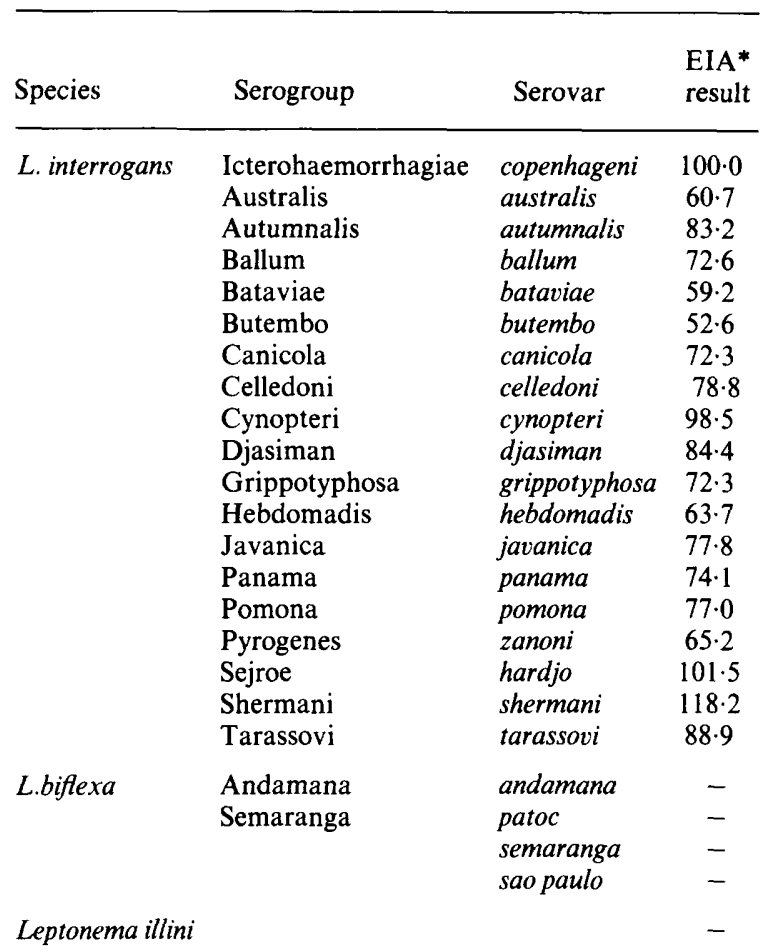

* Expressed as percentage of OD at $488 \mathrm{~nm}$ obtained with heterologous EIA compared with homologous copenhageni EIA $(\mathrm{OD}=1 \cdot 35) ;-=$ EIA OD $<$ background

sults not shown). The MABs could not passively protect newborn guinea-pigs from lethal challenge, even when amounts of $1 \mathrm{mg}$ of MAB/day were administered for periods of up to 5 days after challenge.

\section{Nature of the antigen}

OE prepared from $L$. interrogans serovars hardjo, pomona and copenhageni was electrophoretically resolved on SDS-polyacrylamide $15 \% \mathrm{w} / \mathrm{v}$ gels and stained with silver, or Western blotted and stained with dilutions of MAB. Silver staining of resolved $\mathrm{OE}$ revealed the presence of numerous bands in the antigen preparations (fig. 1a). Some were common to all 3 serovars whereas others were unique. There was also a diffuse band in the $(20-30) \times 10^{3}$-mol. wt region of the gel which resembled the profile obtained when purified serovar copenhageni LPS was resolved and stained with a carbohydratespecific silver stain (fig. 1b). This diffuse band in the OE preparation was shown to be LPS by

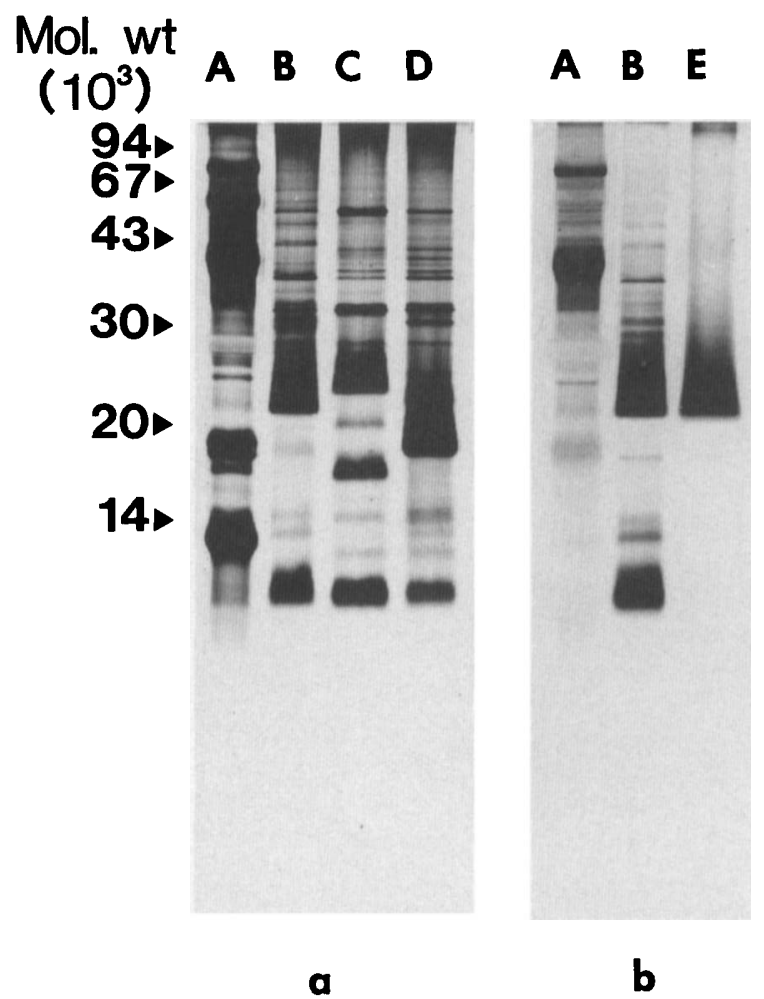

Fig. 1. SDS-PAGE of leptospiral antigens: (a) profile obtained by protein silver-staining; (b) profile obtained by carbohydrate silver-staining. Lanes: (A) Mol. wt marker proteins; (B) $10 \mu \mathrm{g}$ serovar copenhageni $\mathrm{OE}$; (C) $10 \mu \mathrm{g}$ serovar pomona $\mathrm{OE}$; (D) $10 \mu \mathrm{g}$ serovar hardjo $\mathrm{OE}$; (E) $5 \mu \mathrm{g}$ serovar copenhageni LPS.

immunostaining with the anti-LPS MAB (Jost et al., 1986; fig. 2b). Purified F9-10 IgG $50 \mu \mathrm{g} / \mathrm{ml}$ was incubated with blotted OE. The MAB reacted strongly with a $35 \times 10^{3}$-mol. wt band in the $\mathrm{OE}$ preparation and also to a lesser extent with bands at mol. wts $\left(10^{3}\right) 51$ and 62 (fig. 2a). Reaction of F910 with the $35 \times 10^{3}-\mathrm{mol}$. wt band was also seen in leptospiral sonicate antigen (fig. 2a). The other 23 MABs reacted in identical manner to F9-10 with the $\mathrm{OE}$ in Western blotting experiments. The profiles obtained with these MABs resembled that of a previously reported anti-leptospiral MAB (Adler and Faine, 1983b). To determine the chemical nature of the epitopes to which the MABs were directed, blotted OE was treated with proteinase $\mathrm{K}$ or periodate and stained with F9-10 as previously described (fig. 3). Treatment with proteinase $\mathrm{K}$ completely eliminated reaction of F9-10 with the major $35 \times 10^{3}-\mathrm{mol}$. wt band whereas the control blot was unaffected. Treatment of the blotted $\mathrm{OE}$ with periodate did not alter the binding of antibody indicating that protein and not terminal reducing sugars are important in the determinants. 


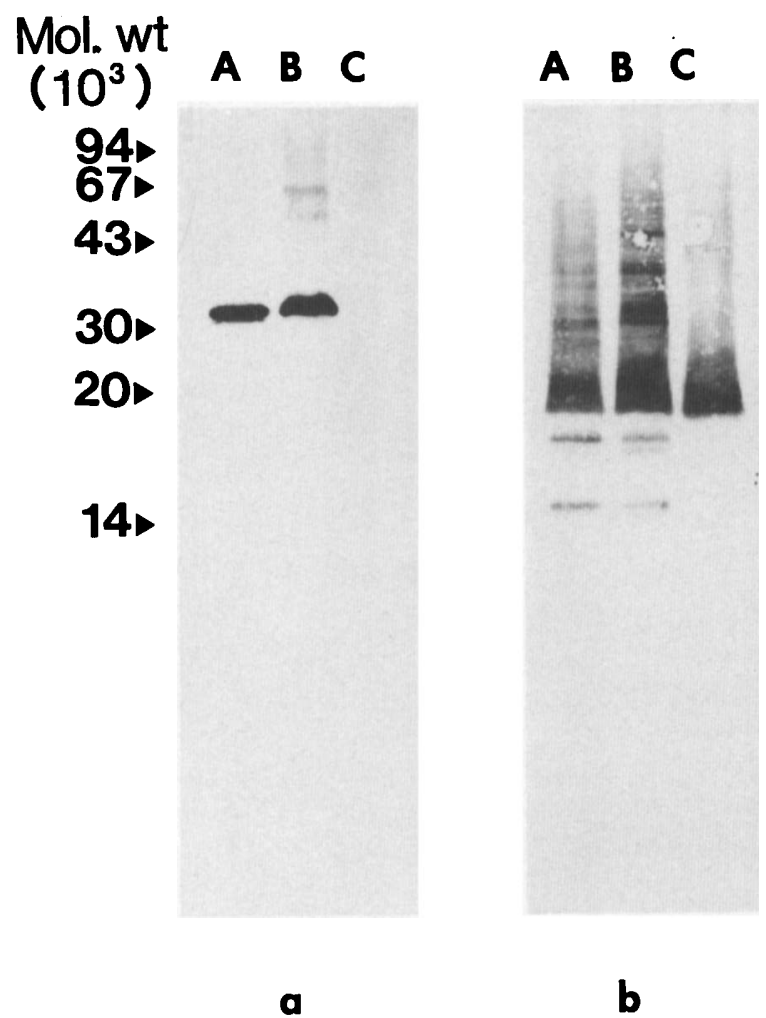

Fig. 2. Western blot analysis of resolved serovar copenhageni antigens: (a) profile obtained by staining with F9-10 IgG (antiOE) $50 \mu \mathrm{g} / \mathrm{ml}$; (b) profile obtained by staining with F1-1 IgA (anti-LPS) $50 \mu \mathrm{g} / \mathrm{ml}$. Lanes: (A) $20 \mu \mathrm{g}$ sonicate antigen; (B) $20 \mu \mathrm{g}$ $\mathrm{OE}$; (C) $5 \mu \mathrm{g}$ LPS.

Reaction of F9-10 with blotted leptospiral sonicate antigens from other $L$. interrogans serovars produced a similar pattern of staining (not illustrated), regardless of the identity of the $L$. interrogans serovar used, demonstrating the species-specificity of the epitope with which F9-10 reacts. F9-10 did not react in Western blotting experiments with either L. biflexa serovar patoc or Leptonema illini sonicate antigens.

\section{Affinity purification of the $35 \times 10^{3}-\mathrm{mol}$. wt $O E$ protein}

By means of affinity chromatography, a small amount of purified OE protein (designated p35) was obtained. This antigen was electrophoresed, blotted and immunostained with F9-10 MAB as previously described. Staining with the MAB revealed a single band at $35 \times 10^{3}$ mol. wt which corresponded to the $35 \times 10^{3}-\mathrm{mol}$. wt band in the untreated $\mathrm{OE}$ (fig. 4). There was insufficient

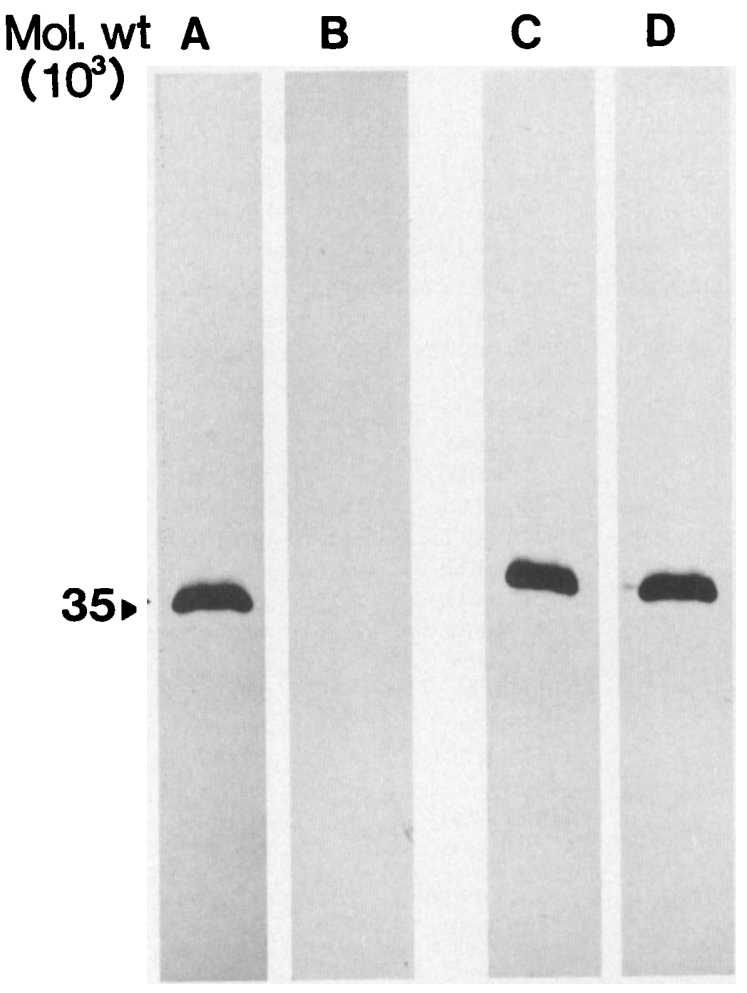

Fig. 3. Western blot analysis of $20 \mu \mathrm{g}$ of serovar copenhageni $\mathrm{OE}$ resolved on a $10 \% \mathrm{w} / \mathrm{v}$ SDS-polyacrylamide gel and stained with F9-10 IgG $50 \mu \mathrm{g} / \mathrm{ml}$ following treatment with: Lanes (A) buffer (control); (B) proteinase K ; (C) buffer (control); (D) periodate.

material available to determine whether the bands at mol. wts $\left(10^{3}\right) 51$ and 62 were co-purified.

\section{Location of the $35 \times 10^{3}-\mathrm{mol}$. wt antigen on the leptospire}

Immunogold labelling of leptospires and ultrathin leptospiral sections were used to define the structural location of the epitopes with which the MABs reacted. During centrifugation of the leptospires before the immunogold labelling experiments, much of the outer layer of the leptospires was removed. However, in several areas the outer layer remained intact and F9-10 bound specifically to this structure but not to the underlying protoplasmic cylinder (fig. 5). No reaction of the MAB was noted with the flagellum (fig. 5) or interior components of the cell (not illustrated).

\section{Discussion}

Although there have been extensive studies on leptospiral LPS antigens (Shinagawa and Yana- 


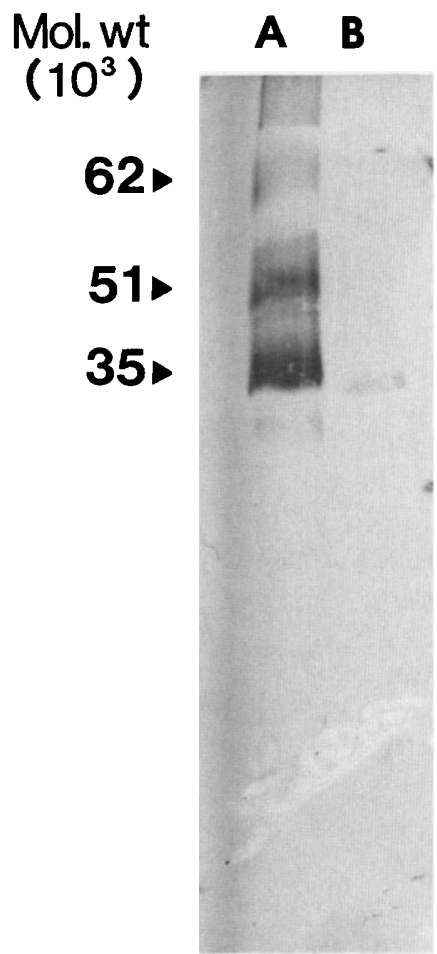

Fig. 4. Western blot analysis of serovar copenhageni $\mathrm{OE}$ proteins stained with F9-10 50 $\mu \mathrm{g} / \mathrm{ml}$. Lanes (A) $20 \mu \mathrm{g} \mathrm{OE} \mathrm{;} \mathrm{(B)} 1 \mu \mathrm{g}$ affinitypurified OE protein.

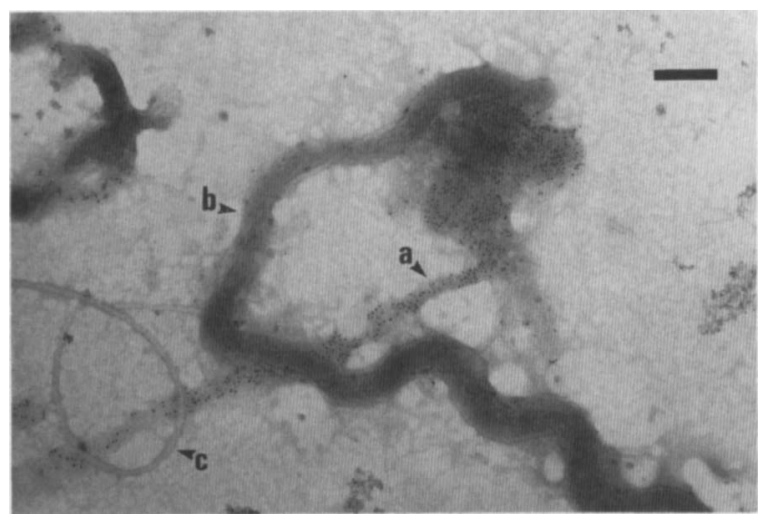

Fig. 5. Immunogold labelling of serovar copenhageni with F9-10 $200 \mu \mathrm{g} / \mathrm{ml}$ showing reaction with detached outer envelope (a) but not with protoplasmic cylinder (b) or flagellum (c); bar $=200 \mathrm{~nm}$.

gawa, 1972; Adler et al., 1980; Ono et al., 1984; Vinh et al., 1986) there is little information available about the protein antigens of Leptospira and their role in immunity. Previous work has shown that antigens in the leptospiral OE are immunogenic and confer immunity to leptospirosis (Auran et al., 1972; Bey et al., 1974; Glosser et al., 1974; Bey and
Johnson, 1978a, $b, 1982$; Broughton and Scarnell, 1985). The antibodies produced in response to this immunogen were agglutinating and produced only serovar-specific (Bey and Johnson, 1982) or limited intra-serogroup immunity (Auran et al., 1975). The antigens responsible for the protective capacity were not characterised and we have herein attempted to define some of the OE antigens by use of MABs.

The 24 MABs selected for study were speciesspecific, did not agglutinate leptospires nor passively protect animals from infection with the homologous serovar. The MABs all reacted identically with a $35 \times 10^{3}$-mol. wt protein found in all serovars of pathogenic, but not saprophytic leptospires tested. These MABs reacted identically with a previously reported anti-leptospiral MAB, D5 (Adler and Faine, 1983b) which was shown to be species-specific but the reacting antigen was not identified. The determinant with which the MABs reacted was also found to lesser extents in protein species of mol. wts $\left(10^{3}\right) 51$ and 62 which correspond approximately to some of the putative surfaceexposed proteins of Nunes-Edwards et al. (1985). It is not possible to conclude whether these proteins share a common epitope or whether the highermol. wt proteins were complexed or contaminated with trace amounts of the $35 \times 10^{3}$-mol. wt protein.

From the PAGE profile of leptospiral OE, it is apparent that the preparation was not pure. As well as containing many different protein species, it contained a significant amount of contaminating LPS. It has already been shown that LPS and outer membrane proteins (OMPs) from other bacteria can form close, possibly covalent, associations that make the antigens difficult to separate for analysis (Poxton et al., 1985).

It is also well documented that agglutinating antibodies directed against the leptospiral LPS are opsonic and protective (Adler and Faine, 1978a, $b$; Jost et al., 1986; Farrelly et al., 1987), unlike the MABs reacting with the leptospiral OE. A similar situation was observed with other organisms, such as Pseudomonas aeruginosa (Hancock et al., 1982; Sawada et al., 1984), in which the MABs directed against the OMPs were also non-agglutinating and were species specific or, at least, more widely crossreactive than the anti-LPS MABs. In passive protection experiments, the anti-LPS MABs were more protective than those MABs directed against the OMPs (Sawada et al., 1984), even though both LPS and OMPs are the major exposed components in gram-negative cells. Although the OMPs of $P$. aeruginosa and the $\mathrm{OE}$ proteins of $L$. interrogans appear to be located in the outer cell walls of these 
organisms, there is no evident explanation as to why they do not elicit agglutinating antibodies. Possibly the OMPs are embedded deeper in the cell wall than the LPS or, as suggested by Sawada et al. (1984), the OMPs may be situated at the base of the protruding LPS.

OE preparations have been described and used for immunisation of various animal species in bacterins currently used as veterinary vaccines (Glosser et al., 1974; Bey and Johnson, 1978a, b, 1982; Broughton and Scarnell, 1985). Takashima and Yanagawa (1975) attempted to define the protective fractions in leptospiral cell walls. They found that the protein fraction of $\mathrm{OE}$ was relatively ineffective as a protective antigen. From our study of these protein antigens with MABs, it appears that the proteins might not be important in protection. It seems likely that the LPS contaminating the $\mathrm{OE}$ preparations elicits the agglutinating, protective, serovar-specific antibodies found in animals immunised with these bacterins. Although there may be other protective antigens in the leptospiral $\mathrm{OE}$, previous work by Nunes-Edwards et al. (1985) suggests that $\mathrm{OE}$ proteins detected by the MABs may be the major surface-exposed OMPs. It is not known whether the other putative protective antigens would elicit significant protective immune responses. Production of MABs against these other antigens would be necessary for investigation of this possibility.

It is possible that the most immunodominant antigen in the leptospiral OE is LPS, because the

\section{REFERENCES}

Adler B, Faine S 1976 Susceptibility of mice treated with cyclophosphamide to lethal infection with Leptospira interrogans serovar pomona. Infection and Immunity 14: 703708.

Adler B, Faine S 1978a The antibodies involved in the human immune response to leptospiral infection. Journal of Medical Microbiology 11 : 387-400.

Adler B, Faine S $1978 b$ Serological and protective-antibody responses of rabbits to leptospiral antigens. Journal of Medical Microbiology 11:401-409.

Adler B, Faine S, Yanagawa R 1980 Comparative studies on two antigens (F4 and TM) extracted from leptospires. Journal of Clinical Microbiology 12:7-9.

Adler B, Faine S 1983 a A pomona serogroup-specific, agglutinating antigen in Leptospira, identified by monoclonal antibodies. Pathology 15:247-250.

Adler B, Faine S $1983 b$ Species- and genus-specific antigens in Leptospira, revealed by monoclonal antibodies and enzyme immunoassay. Zentralblatt für Bakteriologie, Parasitenkunde, Infektionskrankheiten und Hygiene, Abteilung I, Originale Reihe A 255:317-322.

Anderson D L, Johnson R C 1968 Electron microscopy of immune disruption of leptospires: Action of complement and lysozyme. Journal of Bacteriology $95: 2293-2309$. antibodies produced in animals immunised with OE bacterins are agglutinating and predominantly serovar-specific, although in these studies, as the antibody response is measured only by MAT, antibodies against other non-agglutinating antigens would not be detected. This corresponds to the type of antibody response seen in LPS-immunised rabbits (Adler and Faine, 1978b) and hamsters (B. H. Jost, unpublished observations). The lack of species immunity in naturally acquired leptospirosis may be due to lack of major species-specific antigens that elicit protective antibodies. There are no data available on the human response to $\mathrm{OE}$ bacterins, although sera from infected human patients do react with the major $\mathrm{OE}$ proteins by Western blotting (B. H. Jost, unpublished observation).

Although our results do not show a role for the $35 \times 10^{3}$-mol. wt protein species antigen in immunity, the antibodies directed against it may be useful in providing a simple, rapid method for the identification of clinical isolates as pathogenic $L$. interrogans without the need for time-consuming biochemical or conventional serological methods. Indeed such an application has already been reported (Jost et al., 1987).

We thank Khim Hoe and Margaret Goodman for their excellent technical assistance in preparing and labelling the immunogold sections. This work was supported by a grant from the National Health and Medical Research Council, Canberra, Australia.

Auran N E, Johnson R C, Ritzi D M 1972 Isolation of the outer sheath of Leptospira and its immunogenic properties in hamsters. Infection and Immunity 5 : 968-975.

Auran N E, Johnson R C, Alexander A D 1975 Chemical and serological activity of leptospiral outer envelope. Leptospira and other Spirochaeta, Proceedings of the National Symposium on Leptospirosis, Bucharest, Romania, pp 277-286.

Barbour A G, Tessier S L, Hayes S F 1984 Variation in a major surface protein of Lyme disease spirochetes. Infection and Immunity 45: 94-100.

Bey R F, Auran N E, Johnson R C 1974 Immunogenicity of whole cell and outer envelope leptospiral vaccines in hamsters. Infection and Immunity 10:1051-1056.

Bey R F, Johnson R C 1978a Humoral immune response of dogs vaccinated with leptospiral pentavalent outer envelope and whole culture vaccines. American Journal of Veterinary Research 39:831-836.

Bey R F, Johnson R C $1978 b$ Humoral immune responses of cattle vaccinated with leptospiral pentavalent outer envelope and whole culture vaccines. American Journal of Veterinary Research 39: 1109-1114.

Bey R F, Johnson R C 1982 Immunogenicity and humoral and cell-mediated immune responses to leptospiral whole cell, outer envelope and protoplasmic cylinder vaccines in hamsters and dogs. American Journal of Veterinary Research 43: $835-840$. 
Broughton E S, Scarnell T 1985 Prevention of renal carriage of leptospirosis in dogs at vaccination. Veterinary Record 117: $307-311$

Faine S, van der Hoeden J 1964 Virulence linked colonial and morphological variation in Leptospira. Journal of Bacteriology 88: 1493-1496.

Farrelly H E, Adler B, Faine S 1987 Opsonic monoclonal antibodies against lipopolysaccharide antigens of Leptospira interrogans serovar hardjo. Journal of Medical Microbiology 23: $1-7$.

Glosser J W, Johnson R C, Sulzer C R, Auran N E 1974 Immunogenic properties of a leptospiral outer envelope bacterin in hamsters and foxes. American Journal of Veterinary Research 35:681-684.

Hancock R E W, Wieczorek A A, Mutharia L M, Poole K 1982 Monoclonal antibodies against Pseudomonas aeruginosa outer membrane antigens: Isolation and characterization. Infection and Immunity 37:166-171.

Hawkes R, Niday E, Gordon J 1982 A dot-immunobinding assay for monoclonal and other antibodies. Analytical Biochemistry 119: 142-147.

Hitchcock P J, Brown T M 1983 Morphological heterogeneity among Salmonella lipopolysaccharide chemotypes in silverstained polyacrylamide gels. Journal of Bacteriology 154:269-277.

Johnson R C 1977 The Spirochetes. Annual Review of Microbiology 31 : 89-106.

Johnson R C, Faine S 1984 In: Bergey's Manual of systematic bacteriology, vol. 1, Williams and Wilkins, Baltimore, MD, pp 62-67.

Jost B H, Farrelly H E, Adler B, Faine S 1987 Identification of Leptospira by species-specific monoclonal antibody. Tropical and Geographical Medicine 39:S512-513.

Jost B H, Adler B, Vinh T, Faine S 1986 A monoclonal antibody reacting with a determinant on leptospiral lipopolysaccharide protects guinea-pigs against leptospirosis. Journal of Medical Microbiology 22:269-275.

Morrissey J H 1981 Silver stain for proteins in polyacrylamide gels: A modified procedure with enhanced uniform sensitivity. Analytical Biochemistry 117:307-310.
Nunes-Edwards P L, Thiermann A B, Bassford P J, Stamm L V 1985 Identification and characterization of the protein antigens of Leptospira interrogans serovar hardjo. Infection and Immunity 48:492-497.

Ono E, Naiki M, Yanagawa R 1984 Isolation of an antigenic oligosaccharide fraction from Leptospira interrogans serovar canicola with a monoclonal antibody. Journal of General Microbiology 130:1429-1435.

Poxton I R, Bell G T, Barclay G R 1985 The association on SDS-polyacrylamide gels of lipopolysaccharide and outer membrane proteins of Pseudomonas aeruginosa as revealed by monoclonal antibodies and Western blotting. FEMS Microbiology Letters 27:247-251.

Sawada S, Suzuki M, Kawamura T, Fujinaga S, Masuho Y, Tomibe K 1984 Protection against infection with Pseudomonas aeruginosa by passive transfer of monoclonal antibodies to lipopolysaccharide and outer membrane proteins. Journal of Infectious Diseases 150:570-576.

Shinagawa M, Yanagawa R 1972 Isolation and characterization of a leptospiral type-specific antigen. Infection and Immunity 5:12-19.

Takashima I, Yanagawa R 1975 Immunizing effects of structural components of Leptospira icterohaemorrhagiae. Zentralblatt für Bakteriologie, Parasitenkunde, Infektionskrankenheiten und Hygiene, Abteilung I, Originale Reihe A 233:93-98.

Towbin H, Staehelin T, Gordon J 1979 Electrophoretic transfer of proteins from polyacrylamide gels to nitrocellulose sheets: Procedure and some applications. Proceedings of the National Academy of Sciences of the USA 76:4350-4354.

Tu V, Adler B, Faine S 1982 The role of macrophages in the protection of mice against leptospirosis: in vitro and in vivo studies. Pathology 14:463-468.

Vinh T, Adler B, Faine S 1986 Ultrastructure and chemical composition of lipopolysaccharide extracted from Leptospira interrogans serovar copenhageni. Journal of General Microbiology 132: 103-109.

Woodward M P, Young W W, Bloodgood R A 1985 Detection of monoclonal antibodies specific for carbohydrate epitopes using periodate oxidation. Journal of Immunological Methods 78: $143-153$. 